\title{
How to Design and Implement a Flipped Classroom Lesson: A Bottom up Procedure for More Effective Lessons
}

\author{
Spyros Papadakis \\ Hellenic Open University, Patras, GREECE \\ Angeliki Gariou-Papalexiou \\ Regional Centre for Educational Planning in Western Greece, Patras, GREECE \\ Nikolaos Makrodimos \\ Ministry of Education and Religious Affairs, Patras, GREECE
}

Received 31 May 2019 • Revised 18 July 2019 • Accepted 27 July 2019

\begin{abstract}
This paper investigates the impact of designing and implementing a Flipped Classroom (FC) learning design at primary and secondary education schools as part of teachers' professional development. During a bottom-up procedure, 376 teachers who participated in a middle-scale seminar for this model were trained in "flipped classroom strategy" with the same blended learning model. In the first phase, they proposed their flipped classroom lesson plans and in the second phase they analyzed them in a peer-review processing. As a result, we have created and propose a learning design template in LAMS available for teachers to author and implement a flipped classroom lesson with the aim of active participation instead of a passive experience.
\end{abstract}

Keywords: flipped classroom, lesson plan, teacher training, learning design.

\section{Introduction}

Teachers are the most important factor affecting learning in schools. The professional development of teachers is one of the factors that impacts on the quality of the educational work. Teachers constantly transform their practice through their experience and participation in formal and informal types of training. Teacher training is crucial to improve and update not only their scientific competence, but also their pedagogical training. It has been shown that the education of teachers is best achieved through the connection of theoretical presentation with practical demonstration, exercise and feedback (Panteliadou \& Patsiodimou, 2000: 152). In the context of new technological conditions, training becomes a prerequisite for the adaptation of both the content and the learning and teaching methods (Vitsilaki, 2002). The role of the teacher is therefore redefined as it must contribute to the formation of a school climate that promotes pupils' self-activity, critical spirit, acumen and spiritual readiness.

A primary goal of in-service teachers training is to provide teachers with requisite pedagogical and technical grounding along with the practice and experience in the design and evaluation of new instruction models. Learning design theory is a new attempt to describe the

(C) Authors. Terms and conditions of Creative Commons Attribution 4.0 International (CC BY 4.0) apply. Correspondence: Angeliki Gariou-Papalexiou, Regional Centre for Educational Planning in Western Greece, 26333 Patras, PO Box 2531, Greece. E-mail: gariou@sch.gr. 
foundational elements of the educational process. Learning designs are "pedagogically informed learning activities which make effective use of appropriate tools and resources" (Fill, Bailey \& Conole, 2008). A learning design describes learning objectives, who does what (and when) using tools and resources, and outcomes. The field of Learning Design seeks to describe the "process" of education - the sequences of activities facilitated by an educator that are often at the heart of small group teaching (Dalziel, 2007).

- The traditional lesson plan is not sufficient for the needs of a "flipped classroom".

- Taking into account the feedback of the trainee teachers, we have reached the design of a revised lesson plan tailored to the requirements of "flipped classroom".

- An effective way of adult learning is the experiential approach, so we have achieved the best results to meet the "flipped classroom" by using the learning model itself.

"Flipped classroom" (FC) is one term used to describe a new pedagogical model allowing increased instructor-students interaction time and an increase in active-learning opportunities for students in classroom. Flipped learning (FL) is a pedagogical approach in which the conventional notion of classroom-based learning is inverted, so that students are introduced to the learning material before class, with classroom time then being used to deepen understanding through discussion with peers and problem-solving activities facilitated by teachers (Higher Education Academy).

For the implementation of the FC, in most of the cases the use of an "online" platform is required. The inclusion of new technologies in the educational process results in a syncretism that combines the use of "traditional" methods, such as communication and collaboration in the classroom, with methods that refer to the use of technological means. This combination of different educational practices in order to create an improved training program is defined by Bersin (2004) as blended learning.

The educational platform used was the Learning Activity Management System (LAMS). The LAMS (https://www.lamsfoundation.org/) is the most widespread and popular platform that implements the ideas of learning design (Dalziel, 2003; Britain, 2004). The LAMS is an Online Free Open Source Software (Papadakis \& Paschalis, 2009) that supports the design, authoring, management and supervision of the execution of courses in the form of sequences of learning activities. LAMS environment was selected due to the diversity of pedagogical tools that it provides to the authors.

In this paper, we present the results of a seven-month study on designing, implementing and evaluating "flipped classroom" pedagogical approaches from teachers in primary and secondary education. We focused on the effective lesson design adapted to the needs of flipped methodology.

We realized that the traditional lesson plan (Greek Pedagogical Institute; Cunningham, 2009) is not sufficient for the needs of a flipped classroom. Thus, we suggested a differentiated lesson plan. About 200 teachers implemented the differentiated lesson plan in their flipped class, on different subjects and levels. We collected their feedback on the application, and we proceeded to re-design the lesson plan. This improved lesson plan designing is presented below.

Our research questions include the following:

1. Can we have a lesson plan tailored to the requirements of a flipped classroom?

2. What are the improvements that teachers themselves propose for the "flipped" lesson plan after the bottom-up implementation? 
Several previous works in the contents of design and implemented flipped classroom model in K-12 education have been published (Uzunboylu \& Karagozlu, 2015; Zainuddin \& Halili, 2016; Akçayır \& Akçayır, 2018).

The flipped classroom is an interesting mix of information technology and creative working atmosphere in the classroom (Chilingaryan \& Zvereva, 2017). The "flipped classroom" provides an opportunity to capture the attention of millennial students and thus improve their learning experience. Advocates of the flipped classroom cite the benefits of having students do hands-on activities in the classroom where the instructor can provide a structured context, and students can get real-time feedback or assistance working with peers and instructional staff (UNC, 2019).

Estes et al. (2014) proposed a three-stage model to flip the classroom: (1) the pre-class (modelling, pre-assessment), (2) in-class (clarifying concepts, solving problems), and (3) postclass (assessment, application, transfer) stages. The initial and final stages (pre and post class) were made by students by distance, at home, using a digital platform and appropriate educational material. Students can view the digital content as many times as they want, they can focus on any points they wish, in their own space and their own pace (Strayer, 2007). Thus, the interaction of students with the teaching material is scaled in a way that does not occur when lectures are given in class (Hertz, 2012). After the "flipped classroom" activities, students can return to the platform and check the level of their knowledge. Depending on their performance and after identifying their possible weaknesses, they can refer again to digital material, watch the video again - from a different viewpoint - or expand their knowledge further if they wish (Estes et al., 2014). The intermediate stage (in-class) takes place in the classroom, using active and participatory teaching techniques (Gariou-Papalexiou et al., 2017). In the "flipped classroom" students are asked to combine the information they acquired outside the classroom and interact with it and their peers in a way to show that they have become active users of information, based on their personal experiences, opportunities, critical thinking and interaction through group activities (Bergmann et al., 2011).

The need for a new lesson plan design emerges from the differentiation of pre-class, in-class and post-class educational preparation.

The literature review shows that lesson designing, as teachers' responsibility, is one of the most important elements in many educational systems all over the world, defining the lesson designing as the "systematic process of deciding what and how students should learn" (Cicek \& Tok, 2014). By trying to analyze the main components of a successful lesson design, we conclude with three main sections: a) the learning objectives or the desired results, b) the learning activities and c) the evaluation of understanding or the evidence of learning (Skowron, 2001; Milkova, 2012). Starting with the first section, the formulation of the learning objectives properly obtained has been mentioned as one of the major problems in lesson designing (Gülten, 2013; Ruys, Keer \& Aelterman, 2012; Gafoor \& Farooque, 2010). Regarding the second section, researchers claim that "an effective lesson design focuses primarily on designing the students' activities rather than designing what the teacher will do" (Froelich, 2009).

Lesson designing is necessary not only for the basic instruction but for different instructional styles like integrated instruction or differentiated instruction or even problem-based learning instruction, as well (Skowron, 2001). Although many researchers highlight the great importance of lesson designing especially in differentiated instruction, at the same time they recognize it as a difficult process (Baker \& Fleming, 2005) and emphasize on the need of teachers' collaboration in designing a lesson (Fujii, 2016). 


\section{Research methodology}

This research was conducted in the Regional Training Center of Patras, Greece (http://pek-patras.ach.sch.gr/), at three stages' seminars.

The first seminar entitled "Flipped Classroom and its technological support" was designed and implemented by the authors of this work who had research experience from the application of the flipped classroom model, at postgraduate level. Its duration was 40 hours, of which 16 were place-based and 24 by distance. The seminar started at 6 November 2017 and was completed on 14 January 2018. The aim of this first seminar was to create 40 educated teachers for the FC model. Shortly after the completion of the seminar, the 40 educated teachers (19 from primary education and 21 from secondary school) were used as trainers in a middle-scale seminar with the same theme.

In the second seminar, 240 teachers were educated in the FC model. Its duration was 36 hours, of which 16 were face-to-face and 20 by distance. The seminar was held in 24 school units between February and April 2018. The training teachers formed groups and were then used as trainers in the third seminar. In this, 96 teachers were educated during 36 hours of training (16h f2f and 2oh by distance), between May and June 2018, held in 6 school units (Table 1).

Since training is a time-limited intervention, the planners of this training have taken into account how best to transfer and integrate the acquired learning experience into the learning life and the working environment of teachers. Thus, the training was implemented on the model of "Flipped classroom" using the model itself in the process. In total, 376 participants were educated in the FC model.

Table 1. The general structure of the three-stages' Seminar

\begin{tabular}{|c|c|c|c|c|}
\hline $\begin{array}{c}\text { Number } \\
\text { of } \\
\text { seminar }\end{array}$ & $\begin{array}{c}\text { Aim of } \\
\text { seminar }\end{array}$ & Participants & Duration & $\begin{array}{c}\text { Teaching } \\
\text { method } \\
\text { used }\end{array}$ \\
\hline $\mathbf{1}^{\text {st }}$ seminar & $\begin{array}{c}\text { To create teacher } \\
\text { trainers in FC } \\
\text { model }\end{array}$ & $\begin{array}{l}40 \text { teachers (they } \\
\text { were used as } \\
\text { trainers to the } 2^{\text {nd }} \\
\text { and } 3^{\text {rd }} \text { seminars) }\end{array}$ & $\begin{array}{c}40 \text { hours } \\
(16 \mathrm{~h} \text { on site }- \\
24 \mathrm{~h} \text { by distance) }\end{array}$ & FC model \\
\hline $\mathbf{2}^{\text {nd }}$ seminar & $\begin{array}{l}\text { To train class } \\
\text { teachers in FC } \\
\text { model }\end{array}$ & 240 class teachers & $\begin{array}{c}36 \text { hours } \\
\text { (16 on site }- \\
\text { 2oh by distance) }\end{array}$ & FC model \\
\hline $\mathbf{3}^{\text {rd }}$ seminar & $\begin{array}{c}\text { To train more } \\
\text { class teachers in } \\
\text { FC model }\end{array}$ & 96 class teachers & $\begin{array}{c}36 \text { hours } \\
(16 \text { h on site }- \\
\text { 20h by distance) }\end{array}$ & FC model \\
\hline Total & & 376 & $40 / 36$ hours & \\
\hline
\end{tabular}

During the second week of their seminar, all the 376 participants of the 3 seminars were asked to design a lesson plan on a subject of their choice and implement this lesson in their class using the FC model. For this purpose, a lesson plan form was given to them to help them in designing their first lesson with the FC model (Table II).

Table 2. Lesson plan

\begin{tabular}{|c|l|}
\hline Date & \\
\hline Subject & \\
\hline Class & \\
\hline Unit & \\
\hline Instructor & \\
\hline Cognitive aims & \\
\hline Learning outcomes & \\
\hline Teaching method & \\
\hline Materials & \\
\hline
\end{tabular}




\begin{tabular}{|c|l|}
\hline $\begin{array}{c}\text { Short description of the } \\
\text { teaching stages }\end{array}$ & \\
\hline Students' activities & \\
\hline Assessments & \\
\hline References & \\
\hline
\end{tabular}

The Learning Activity Management System (LAMS) was used as the main platform for the communication and implementation of the Seminar work and for the design and development of the digital courses.

Thus, during the procedure they were asked to transform their lesson plan documents in a sequence of learning activities (learning design) using the LAMS platform and then upload their lesson plans on the LAMS community. An example is shown below (Figure 1):

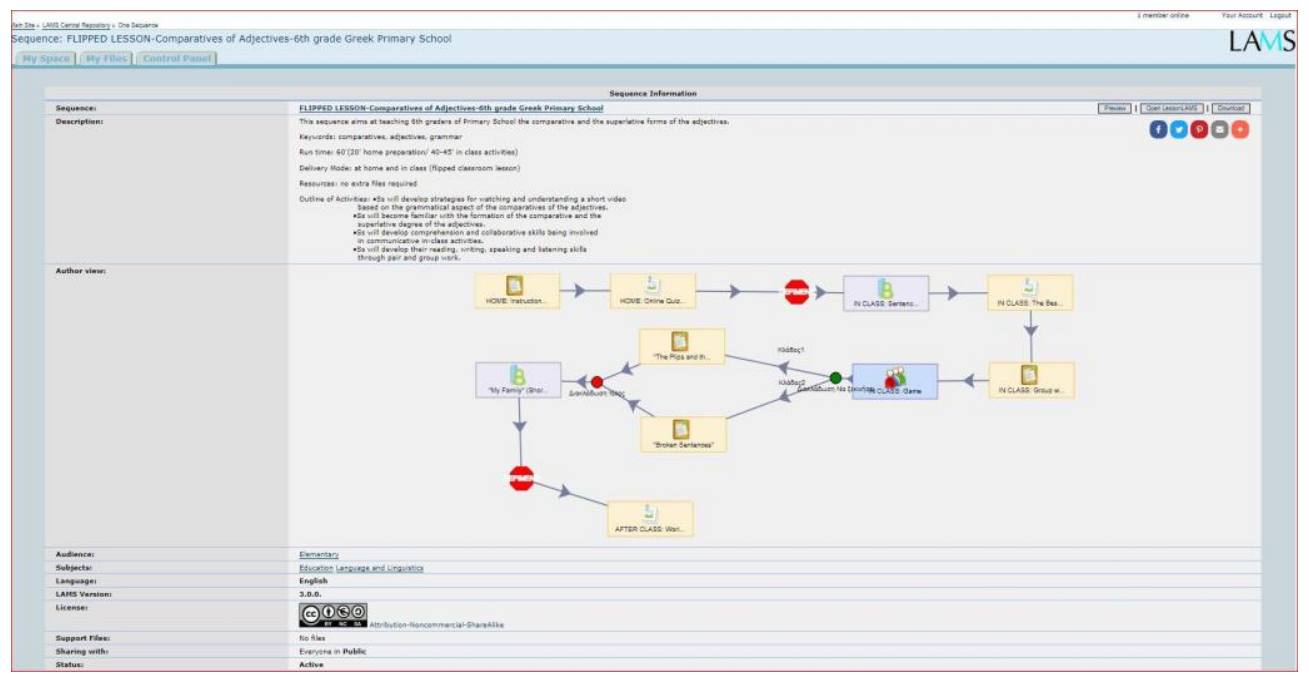

Figure 1. The design of learning activities of an "English Language - Flipped Classroom" course: https://lamscommunity.org/lamscentral/sequence?seq id=2215658

After the end of the $1^{\text {st }}$ teachers' training seminar evaluation, the need for a dedicated FC learning design was raised. Thus, we designed an FC lesson plan template (Table 3).

Table 3. Flipped Classroom Lesson Plan Template

\begin{tabular}{|c|c|}
\hline Grade level & \\
\hline Subject area & \\
\hline Lesson title & \\
\hline Time needed & \\
\hline Teacher & \\
\hline Number of students & \\
\hline Prerequisite skills or knowledge & \\
\hline Learning objectives & \\
\hline PRE CLASS & \\
\hline $\begin{array}{c}\text { Student learning resources with a short description (notes, } \\
\text { books, maps, videos, presentations, websites, } \text { etc.) }\end{array}$ & \\
\hline $\begin{array}{c}\text { Authors of the above learning material and the duration } \\
\text { (especially for videos) }\end{array}$ & \\
\hline $\begin{array}{c}\text { Student learning activities at home (answering video } \\
\text { embedded questions, solving problems, writing summaries, } \\
\text { surveys or essays, etc.) }\end{array}$ & \\
\hline $\begin{array}{c}\text { Reviewing students' work prior to class (through LMS } \\
\text { platforms or other way) }\end{array}$ & \\
\hline
\end{tabular}


S. Papadakis, A. Gariou-Papalexiou \& N. Makrodimos - How to Design and Implement ...

\begin{tabular}{|c|c|}
\hline $\begin{array}{c}\text { Differentiating the design of in class activities depending on the } \\
\text { above feedback }\end{array}$ & \\
\hline IN CLASS & \\
\hline $\begin{array}{c}\text { Classroom activities (type, detailed description, duration, } \\
\text { materials to prepare) }\end{array}$ & \\
\hline Formative assessment & \\
\hline POST CLASS & \\
\hline Summative assessment through online tests or projects & \\
\hline Challenging activities for high performers & \\
\hline
\end{tabular}

At the end of the seminar, all the participants were asked to evaluate their peers' lesson plans on the LAMS community and fill a questionnaire with their answers.

\section{Results}

During that medium-range seminar, 276 learning designs (sequences of learning activities) from teachers were uploaded on the LAMS community (LAMS Central Repository, http://lamscommunity.org/lamscentral/). After that, the teachers were asked to evaluate the above learning designs by filling in an online form made by the designers of the seminars. The questions of the form were based on our flipped classroom learning design template combined with the revised Bloom cognitive skills pyramid (Anderson \& Krathwohl, 2001, Figure 2).

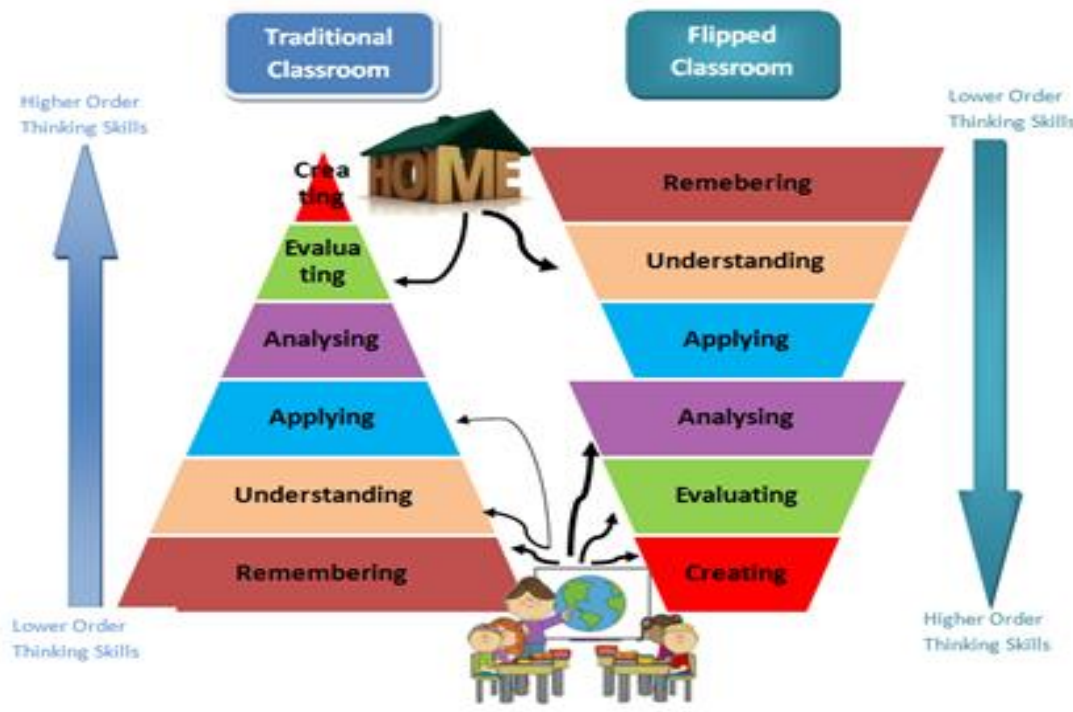

Figure 2. Improving learning to think in a flipping class (Gariou-Papalexiou et al., 2017)

The answers of the trainees - evaluators are presented below.

\subsection{Starting from the base of the pyramid, with the skill of memorizing}

Writing the cognitive objectives on the lesson plan:

- Half of the lesson plans (50.4\%) were written in a very clear and distinct way. As a result it was easy to measure the degree of achievement of their cognitive objectives. Nearly a third of the plans (37.3\%) contained some general goals, making it more difficult to measure their degree of achievement and only $12.3 \%$ plans were written in a completely indefinite way (Figure 3). 


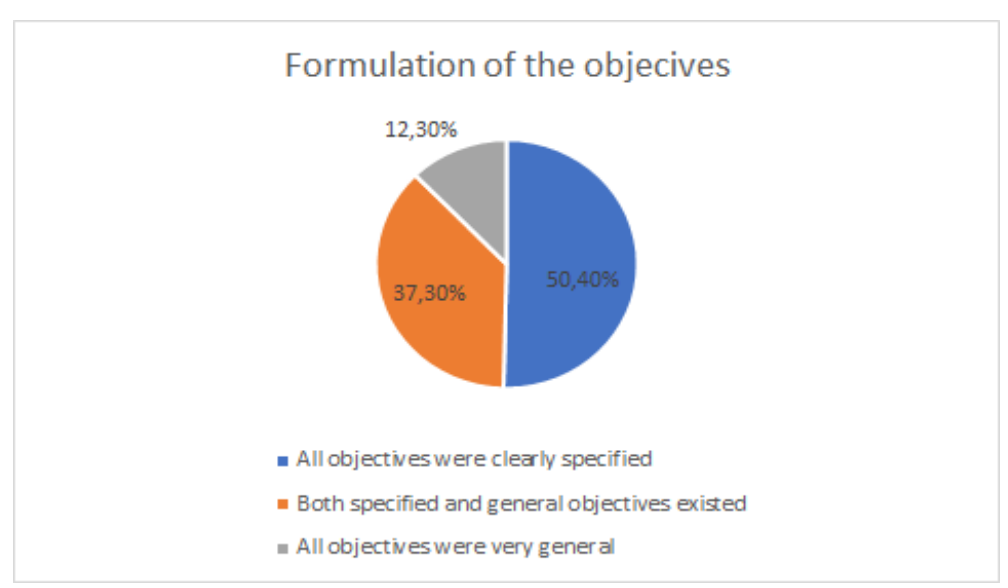

Figure 3. Formulation of the objectives included in the lesson plans Length of video:

- Regarding the duration of videos used in the Pre-Class stage of the Flipped Classroom model, as shown by the form answers, it was kept small (from 1 to 9 minutes) in the overwhelming majority of projects (86.2\%), making it easier for students to watch and memorize new information.

\subsection{Continuing with the cognitive skill of understanding}

- Regarding the kind of cognitive objectives that were included in the lesson plans, almost half of them (44.9\%) were knowledge - deepening objectives, while the rest of them were equally shared to knowledge - creating objectives and knowledge acquiring objectives.

As to the prerequisite knowledge, no reference is made to the vast majority of the lesson plans, only a small percentage of them (16.3\%) refer to the prerequisite knowledge, whereas only $10 \%$ of these plans control the prerequisite knowledge by embedded questions in the video sent at students' home (Figure 4).

\section{Prerequisite knowledge}

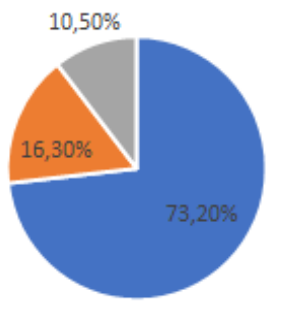

- Prer equiste knowledge was not mentioned at all

- Prer equiste knowledge was mentioned

- Prer equiste knowledge was proved by embeded questions in the "pre-c lass" video

Figure 4. Reference of prerequisite knowledge in the lesson plans

- By examining the degree of interactivity of the videos used in the first stage of the Flipped Classroom model, we observed that almost half of the lesson plans (44.6\%) contained videos with few interactive elements, $28.3 \%$ of the videos offered no 
interaction to the students, while $27.3 \%$ of the videos activated students with many interactive elements such as hyperlinks or embedded questions and tasks.

\subsection{In the middle of Bloom's pyramid we come across the skill of application}

- In terms of the number of objectives, the overwhelming majority (79\%) of the lesson plans contained few objectives that could be achieved comfortably during the in class time. In the rest of the lesson plans, there was a significant probability that the lesson time would not be enough to achieve all the mentioned objectives.

- With regard to classroom activities, in the second part of the flipped class model, as described in the lesson plans, most of them (45.3\%) aim at the higher skills of assessment and creation, a large proportion of them (40.9\%) refers to the Bloom's pyramid middle, in particular the skills of knowledge analysis and application, while only a small percentage (13.8\%) is limited to the basis of the pyramid and to the skills of memorization and comprehension.

- Continuing the assessment of the activities within the class, we observe that in most of the lesson plans (44.6\%) these were exclusively group-based and promoted the cooperation among the students, a significant proportion of lesson plans (37.7\%) contained both individual and group activities and only a small percentage (17.8\%) of projects contained exclusively individual activities (Figure 5).

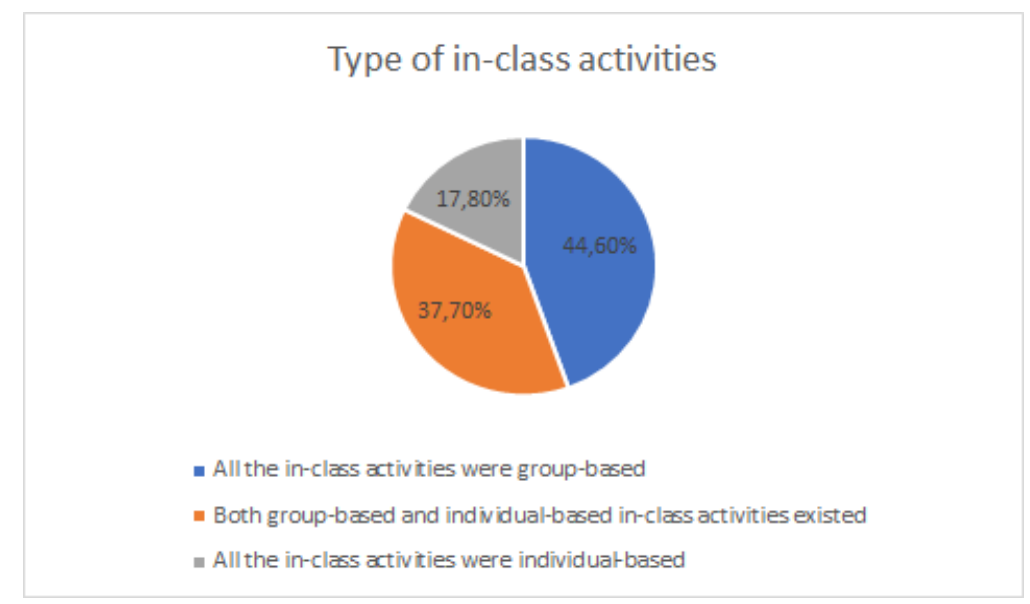

Figure 5. Type of in-class activities

As far as the skill of the analysis was concerned, the quality of the videos and the supervision of the teachers over them was examined.

- Most of the videos (61.2\%) used in the first phase of the Flipped Class model were attractive with rich graphics and clear sound, while almost the rest (35.1\%) were judged to be good for their graphics and sound.

- Many educational digital platforms such as LAMS provide analytical data on student participation and interaction with videos they watch at home. This monitoring feature was fully exploited by only a small percentage of teachers (14.1\%), while in a small percentage of lesson plans (25.7\%) little reference was made to video supervision, while the majority of lesson plans (60.1\%) ignores video supervision and thus, lacks valuable data that could lead to the review and modification of activities within the classroom; like who and how many times watched the video and if the content was understood (Figure 6). 


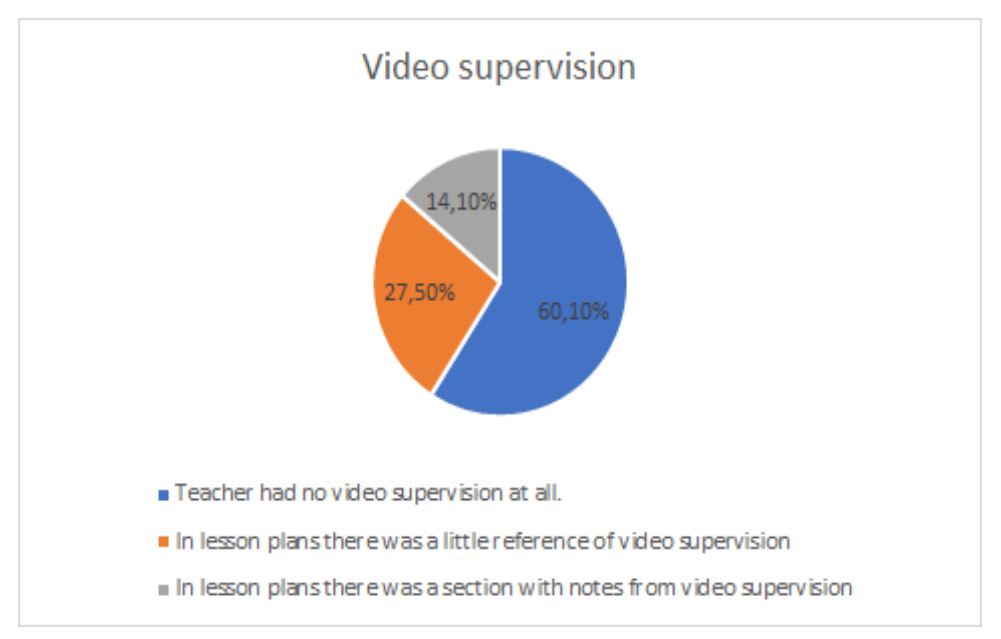

Figure 6. Video supervision

\subsection{The skill of evaluation} in the lesson plans:

Approaching the top of Bloom's pyramid, we examine the cognitive skill of evaluation - The videos selected for the first stage of the Flipped Classroom model were not only short and qualitative but should be appropriate for the lesson to be taught by students. As shown by the lesson plans and the teachers' assessment, the vast majority of the selected videos (67.4\%) covered all the cognitive objectives of the course, while almost the rest of the videos (28.3\%) covered several of the cognitive goals of the lesson.

- The great value of lesson plans lies not only in their first use but also in their ability to be reused by other teachers. For this purpose, the activities carried out within the classroom should be described in detail. As recorded in the evaluation of the lesson plans by the teachers, in their highest proportion (55.8\%), the lesson plans described the activities in detail and were accompanied by worksheets so that they could be reused by other teachers. In a significant proportion of lesson plans (35.1\%), activities were briefly described, while in a small percentage of lesson plans (9.1\%), classroom activities were recorded only as titles (Figure 7).

In class activities' description
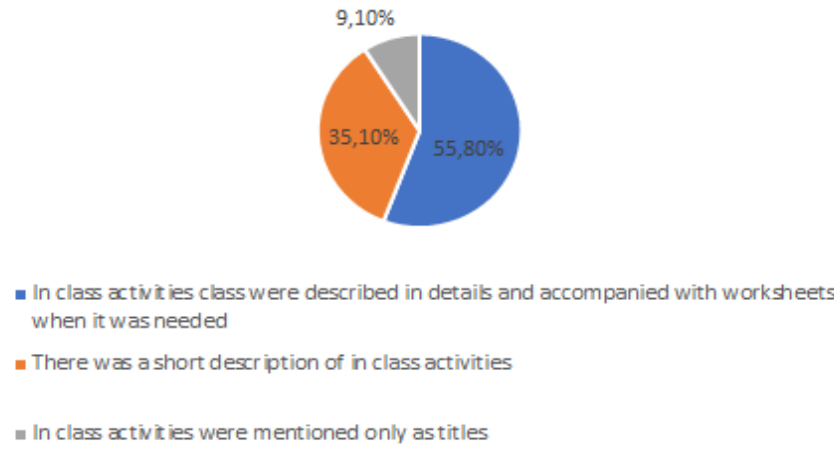

Figure 7. Description of in class activities in lesson plans 
- More than half of the lesson plans (54.7\%) included a complete evaluation of learning objectives, videos and students' activities. Only $11.2 \%$ of the lesson plans were missing any kind of evaluation.

\subsection{The skill of creativity}

plans:

At the top of Bloom's pyramid is creativity. Concerning the videos used in the lesson

- Only a small percentage (5.1\%) of the teachers created their own video from the beginning, while a significant percentage $(28.6 \%)$ of them processed a video from the Internet by resizing it or embedded questions or even added their voice on it. The majority of the teachers (66.3\%) used an appropriate video from the Internet with no editing at all (Figure 8).

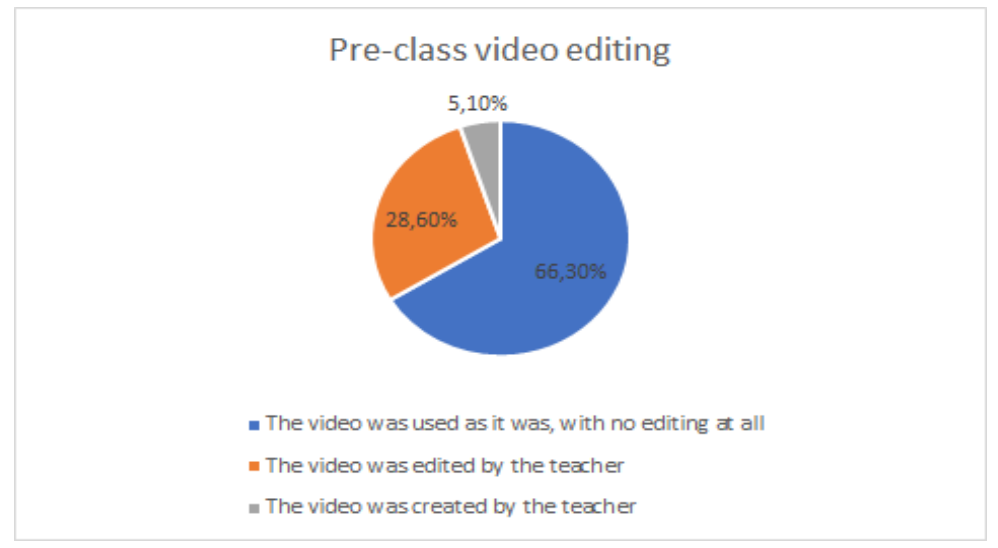

Figure 8. Pre-class video editing

\section{Discussion}

The results of this study clearly show that the structure of the seminar had two strong foundations. The first concerns the training method. Teaching the flipped class model using the model itself is innovative and has the advantage that the trainees have personal experience as students of the model they are about to teach. The second concerns the redesign of the FC lesson plan after the evaluation of the initial plan. The evaluation from the trainees' lesson plans for the flipped classroom model lead us to design a new lesson design template tailored to the needs of the flipped class model.

The success of the first part was shown by the efficient use of the first 40 trainees as trainers in the next parts of the seminar (training 366 teachers) and by the successful implementation of the flipped classroom model in their classrooms. The second part, based on 276 teacher assessments, has led to a satisfactory design of a lesson design template for a flipped classroom that remains to be tested extensively in practice in future research work.

Regarding the results of the lesson plan evaluations, it was expected that our initial hypothesis, that the traditional lesson plan did not fully cover the flipped classroom model, was right. In particular, as the results are categorized based on the revised Bloom's Cognitive Pyramid, the deficiencies in the lesson plan are more pronounced at the top of the pyramid regarding the higher cognitive skills. 
Most trainees were experienced teachers and knew that the cognitive objectives of the lesson plan should be few and clearly written so that their degree of achievement could be easily measured. As to the quality of the objectives, only half of the lesson plans were aimed at deepening knowledge and creation. What was noteworthy was that most of the projects lacked reference to prerequisite knowledge and skills which is supposed to be the critical key to the success of every lesson. On the other hand, almost all trainees had already learned from the seminar theory and their own experience that the videos sent to their students should be short, attractive, appropriate and interactive.

Confirming the change of the latest years in the Greek educational community, the vast majority of lesson plans included group cooperative activities within the classroom. The disappointing results with regard to the feedback that teachers could get from digital platforms such as LAMS and Edpuzzle, which are widely used in the flipped classroom model, can be explained by the fact that most teachers were not familiar with the use of this model and it was their first time they could have feedback before the class.

Almost half of the teachers had foreseen in their lesson plans to evaluate, after the lesson, achievement of cognitive goals, video success and classroom activities.

In terms of creativity, only a few teachers created their own videos from the beginning, perhaps because of a lack of technical knowledge or insecurity, a small percentage of them processed the videos they used, while most of them preferred the confidence of the educational videos found on the Internet.

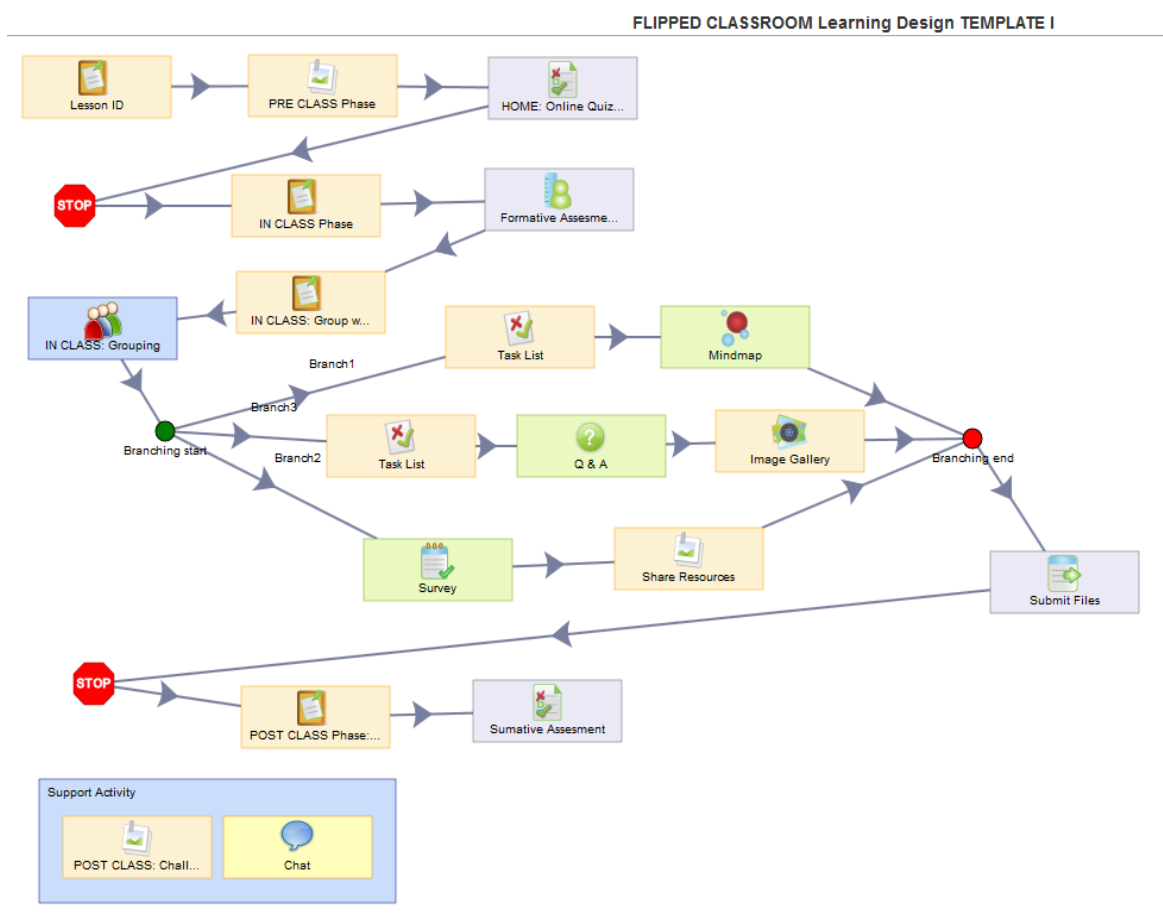

Figure 9. Flipped Classroom Learning Design Template Example in LAMS

\section{Conclusions}

The information we have gathered in this study leads to the conclusion that the traditional lesson plan is not sufficient for the needs of a flipped classroom. We focused on the effective lesson design adapted to the needs of flipped methodology. The whole methodology was applied to a wide variety of levels and objects. More specifically, the study was implemented in 
both primary and secondary education, as well as vocational education. In addition, research covers a medium-scale process in different disciplines.

In addition, an effective way of adult learning is the experiential approach, so we have achieved the best results to meet the "flipped classroom" by using the learning model itself.

Taking into account the feedback of the trainee teachers, we have reached the design of a revised lesson plan tailored to the requirements of a flipped classroom. We propose that the revised lesson plan be used and further tested to flipped classroom lessons. We recommend its use in lessons designed by the flipped class model combined with differentiated strategies or project based learning or game based learning. This revised lesson plan should be tested in "flipped classes" all over the school year if it is possible in combination with differentiated teaching.

\section{Acknowledgements}

editing.

We would like to thank Mrs. Seraphia Savvaidou for her contribution to the English

This research did not receive any specific grant from funding agencies in the public commercial, or nonprofit sectors.

The authors declare no competing interests.

\section{References}

Anderson, L.W., \& Krathwohl, I. (2001). A taxonomy for learning, teaching, and assessing: A revision of Bloom's taxonomy of educational objectives. New York: Longman.

Baker, P.H., \& Fleming, L. C. (2005). Lesson plan design for facilitating differentiated instruction. MidWestern Educational Researcher, 28(4), 35-44.

Bergmann, J., Overmyer, J., \& Wilie, B. (2011). The flipped class: Myths vs. reality. Retrieved from: http://www.thedailyriff.com/articles/the-flipped-class-conversation-689.php.

Bersin, J. (2004). The blended learning book: Best practices, proven methodologies, and lessons learned. San Francisco, CA: Pfeiffer.

Britain, S. (2004). A review of learning design: Concept, specifications and tools. A report for the JISC Elearning Pedagogy Programme. Retrieved from: www.elearning.ac.uk/subjects/ldfold/LD/topic view.

Cicek, V., \& Tok, H. (2014). Effective use of lesson plans to enhance education in us and Turkish kindergarten thru 12th grade public school system: a comparative study. International Journal of Teaching and Education, 2(2), 10-20.

Chilingaryan, K., \& Zvereva, E. (2017). Methodology of flipped classroom as a learning technology in foreign language teaching. Procedia - Social and Behavioral Sciences, 237, 1500-1504.

Cunningham, G. (2009). Lesson plans and unit plans: The basis for instruction. In: The new teacher's companion: practical wisdom for succeeding in the classroom, chapter 7. ASCD.

Dalziel, J. (2003). Implementing learning design: The Learning Activity Management System (LAMS), Sydney: E-learning Centre of Excellence (MELCOE), Macquarie University. Retrieved from: www.melcoe.mq.edu.au/documents/ASCILITE2003\%20Dalziel\%20Final.pdf.

Dalziel, J. (2007). Using LAMS for inquiry-based learning: Keynote presentation for the centre for inquirybased learning in the arts and social sciences (CILASS). Presentation given at LAMS Workshop, 
University of Sheffield, 9 July 2007. Retrieved from: http://www.lamscommunity.org/dotlrn/clubs/educationalcommunity/lamsresearchdevelop ment/forums/attach/go-to-attachment?object id=443758\&attachment id=443760.

Estes, M. D., Ingram, R., Liu, J. C. (2014). A review of flipped classroom research, practice, and technologies. International HETL Review, 4(7). Retrieved from: https://www.hetl.org/feature-articles/areview-of-flipped-classroom-research-practice-and-technologies.

Fill, K., Bailey, C., \& Conole, G. (2008). A toolkit to guide the design of effective learning activities. In: P. Rees, L. Mackay, H. Durham \& D. Martin (Eds.), E-Learning for Geographers. IGI Global: Hershey, PA.

Froelich, J. (2009). Effective lesson design: A basic conceptual outline. Using looking at learning to improve school performance, 1-5. Retrieved from: http://www.lookingatlearning.org/lesson design.html.

Fujii, T. (2016). Designing and adapting tasks in lesson planning: A critical process of Lesson Study. ZDM, 48(4), 411-423.

Gafoor, K. A., \& Umer Farooque, T. K. (2010). Ways to improve lesson planning: A student teacher perspective. Online Submission. https://files.eric.ed.gov/fulltext/ED517056.pdf.

Gariou-Papalexiou, A., Papadakis, S., Manousou, E., \& Georgiadou, I. (2017). Implementing a flipped classroom: A case study of Biology teaching in a Greek high school. Turkish Online Journal of Distance Education - TOJDE, 18(3), 47-65.

Gökçe Akçayır, Murat Akçayır, (2018). The flipped classroom: A review of its advantages and challenges. Computers \& Education, 126, 334-345, https://doi.org/10.1016/j.compedu.2018.07.021

Greek Pedagogical Institute. (2019). Lesson plans. Retrieved from: http://www.pischools.gr/hdtc/material/scenaria.htm (in Greek).

Gülten, A. Z. (2013). Am I planning well? Teacher trainees' voices on lesson planning. Procedia - Social and Behavioral Sciences, 93, 1409-1413.

Hertz, M. (2012). The flipped classroom: Pro and con edutopia. Retrieved from: http://www.edutopia.org/blog/flipped-classroom-pro-and-con-mary-beth-hertz.htm.

Higher Education Academy (2019). Flipped learning. Retrieved from: https://www.heacademy.ac.uk/knowledge-hub/flipped-learning-o.

Milkova, S. (2012). Strategies for effective lesson planning. Center for Research on learning and Teaching, 1-4.

Panteliadou, S., \& Patsiodimou, A. (2000). Attitudes and opinions of teachers for training in special education. Ministry of Education, p. 152 (in Greek).

Papadakis, S., \& Paschalis, G. (2009). Teaching with the Learning Activity Management System LAMS: The teacher's experience. $1^{\text {st }}$ Educational Conference on Integration and use of ICT in educational process, 24-26 April, Volos, Greece (in Greek).

Ruys, I., Keer, H. V., \& Aelterman, A. (2012). Examining pre-service teacher competence in lesson planning pertaining to collaborative learning. Journal of Curriculum Studies, 44(3), 349-379.

Skowron, J. (2001). Powerful lesson planning models. Arlington Heights, IL: Skylight Professional Development.

Strayer, J. (2007). The effects of the classroom flip on the learning environment: a comparison of learning activity in a traditional classroom and flip classroom that used an intelligent tutoring system, $\mathrm{PhD}$ dissertation, Ohio State University.

UNC (2019). Introduction to flipping your class. Center for Faculty Excellence, University of North Carolina. Retrieved from: https://cfe.unc.edu/teaching-and-learning/introduction-flipping-class/.

Uzunboylu, H., \& Karagozlu, D. (2015). Flipped classroom: A review of recent literature. World Journal on Educational Technology, 7(2), 142-147. https://doi.org/10.18844/wjet.v7i2.46 
S. Papadakis, A. Gariou-Papalexiou \& N. Makrodimos - How to Design and Implement ...

Vitsilaki-Soroniati, C. (2002). Lifelong education of teachers: A case study of the primary education upgrade program, Education Sciences, 2, 37-60 (in Greek).

Zainuddin, Z., \& Halili, S. H. (2016). Flipped classroom research and trends from different fields of study. The International Review of Research in Open and Distributed Learning, 17(3). 